\title{
Prevalence of the population 'at risk' of developing colorectal cancer in Sri Lanka
}

\author{
Yasara Manori Samarakoon ${ }^{1 *}$, Nalika Sepali Gunawardena ${ }^{2}$, Aloka Pathirana ${ }^{3}$ \\ ${ }^{1}$ National Cancer Control Programme, Ministry of Health, Sri Lanka; ${ }^{2}$ World Health Organization Country Office, Sri \\ Lanka; ${ }^{3}$ Department of Surgery, Faculty of Medical Sciences, University of Sri Jayewardenepura, Sri Lanka \\ *Correspondence: yasara.samarakoon@gmail.com
}

DOI: https://doi.org/10.4038/jccpsl.v23i4.8115

Received on: 14 July 2017

Accepted on: 5 December 2017

\begin{abstract}
Background: Colorectal cancer is the fourth leading cancer among men and sixth leading cancer among women in Sri Lanka.

Objective: To estimate the prevalence of 'being at risk' of developing colorectal cancer among adults using a colorectal cancer risk prediction model developed and validated to the Sri Lankan setting.

Methods: A community-based cross-sectional descriptive study was conducted among a representative sample of 811 adults aged 30 years and above in the districts of Colombo and Gampaha, selected using a multi-stage cluster sampling technique. The validated risk prediction model in the form of an interviewer-administered questionnaire was used to gather information. The prevalence of those 'at risk' of colorectal cancer was assessed based on a validated cut-off score, and those ‘at risk' were further divided as 'moderate' and 'high risk' based on cut-off values agreed upon by the experts.
\end{abstract}

Results: The age-adjusted prevalence of those 'at risk' was $12.5 \%$ (95\% CI=12.3, 12.7). Age-adjusted prevalence of those at 'moderate' and 'high' risk were $11.8 \%(95 \% \mathrm{CI}=11.6,12.0)$ and $0.72 \%(95 \% \mathrm{CI}=0.7,0.8)$, respectively.

Conclusions: The high prevalence of being 'at risk' of colorectal cancer indicates the necessity of screening for colorectal cancer as a programme in Sri Lanka. Considering the logistic difficulties in offering follow-up diagnostic colonoscopy examinations for all, the study recommends that those found as 'high-risk' be referred for colonoscopy.

Key words: at-risk prevalence, colorectal neoplasm, risk prediction model, Sri Lanka

\section{Introduction}

Being the fourth commonest cancer worldwide as well as in South East Asian countries, colorectal cancer has become an important public health problem globally (1). Though the majority of colorectal cancers have occurred in Western countries, there is evidence of rapid increase in the incidence and mortality in many countries which were previously considered as being at low-risk (2).

According to the latest published cancer incidence 
data by the National Cancer Control Programme in 2010, colorectal cancer is the fourth leading cancer among men and the sixth leading cancer among women in Sri Lanka (3). Colorectal cancer accounted for 6.3\% out of all cancers in both males and females, while the incidence has shown an upward trend over the past years (3).

In colorectal cancer, early detection is associated with better survival (4). An early stage colorectal cancer which has not extended beyond the bowel wall at the time of diagnosis is associated with a five-year survival of more than $90 \%$. However, this decreases up to $60 \%$ for patients with tumours with lymph node involvement, and to less than $10 \%$ if metastases are present. This indicates that colorectal cancer has a better survival if detected and treated at an early stage. The screening tests available for detecting colorectal cancer vary from a simple test such as the faecal occult blood test to more advanced and invasive methods such as flexible sigmoidoscopy and colonoscopy. Most of the developed countries offer colonoscopy or flexible sigmoidoscopy as a screening test for all those above 50 years of age to be done every ten years (5). Limitations in the availability of skilled health personnel, high cost and logistic issues of having to perform this invasive procedure within a health institute are important factors, that have prevented the developing countries considering colonoscopy or flexible sigmoidoscopy as a routine test in their population-level screening programmes.

In the absence of a screening programme for colorectal cancer, Sri Lanka uses flexible sigmoidoscopy or colonoscopy for diagnosing colorectal cancer in patients with symptoms. Clear evidence on its high burden and better survival associated with early detection signifies that Sri Lanka will benefit from introduction of a cost effective and affordable screening programme for colorectal cancer. However, being a low- and middle-income country, Sri Lanka cannot afford to provide colorectal cancer screening services using colonoscopy or flexible sigmoidoscopy to all above 50 years of age. As an alternative, evidence suggests that it would be efficient to follow a twostep process where population groups at risk of colorectal cancer can be identified using a risk prediction tool and thereafter, colonoscopy or flexible sigmoidoscopy offered only to those who are identified as 'being at risk' via this risk stratification (2).
There are many risk prediction models developed in different parts of the world, such as 'Freedman Model', 'Harvard Colorectal Cancer Risk Index,' 'Imperiate's Model' and 'Driver's Model' (6). The 'Freedman Model' has been developed and validated separately for men and women in the United States. The risk factors included are cancer negative sigmoidoscopy/colonoscopy in the last 10 years, polyp history in the last 10 years, history of colorectal cancer in first degree relatives, non-steroidal anti-inflammatory drugs, cigarette smoking, body mass index (BMI), physical activity and fibrous food consumption (7). The 'Harvard Cancer Risk Index' is another comprehensive risk prediction model developed by the Harvard school of Public Health for all cancers (8), while the 'Driver's Model' which includes age, alcohol use, smoking status and BMI has been developed from a cohort study of only males (9). However, the fact that these models and their strengths are specific for a population or setting at which they were estimated, precludes their use in Sri Lanka. This highlights the requirement of country-specific risk prediction models that are developed based on risk factors identified for the country and validated for detecting those 'at risk' for developing colorectal cancer.

Sri Lanka offers free healthcare services and has initiated healthy lifestyle centres (HLCs) at the lowest level of primary care institutions since 2011 to offer adults a structured non-communicable disease (NCD) screening service (10). More than 900 such centres are distributed throughout the country at present. The main service objective of HLCs is to reduce the risk of NCDs of 40-65 year old adults by early detection of risk factors and improving the access for specialized care for those found to be at high-risk. As for colorectal cancer, the first step in introducing a screening programme in Sri Lanka is to establish a referral system and services for those found to be 'at risk' to undergo colonoscopy or flexible sigmoidoscopy in a hospital setting. Advocating for such referral systems with health authorities requires an estimation of the number that is likely to be referred for colonoscopy or flexible sigmoidoscopy. In other words, the information required is the prevalence of those 'at risk' for colorectal cancer among adults. There is lack of evidence pertaining to this locally in Sri Lanka.

In this background, the present study aimed at determining the prevalence of those 'at risk' of colorectal cancer among adults using a risk prediction 
model. This information would form the basis to advocate for a policy decision to include screening for colorectal cancer among the high-risk population during HLCs in Sri Lanka.

\section{Methods}

A community-based descriptive cross-sectional study was carried out in the districts of Colombo and Gampaha in the Western Province of Sri Lanka. These two districts are known to have the largest population with the highest incidence of colorectal cancer (11). Adults aged 30 years and above, with no past history of any type of cancer and permanently residing in the above two districts were the study units of this study.

Estimation of the sample size was based on the minimum number required to detect the expected prevalence of increased risk for developing colorectal cancer among adults (12). Based on an expected prevalence of $50 \%$ with $5 \%$ precision, at $95 \%$ confidence interval along with an allowance for design effect of two and an anticipated non-response of 5\%, the required sample size was rounded off to be 825 (13).

In selecting the sample, multi-stage cluster sampling technique was used. Each district of Colombo and Gampaha comprises 13 district secretariat (DS) divisions and the study was conducted in all 26 DS divisions. A cluster was defined as a group of adults in a Grama Niladhari (GN) division while the cluster size was taken as 25 . In order to recruit 825 participants, the number of clusters to be included in the study was calculated as 33. Clusters were allocated to each DS division with probability proportionate to the size (PPS) of the adult population living in DS divisions. The sampling frame was based on census data 2012 of each GN division. The index house in each cluster was selected randomly from the updated map of respective GN division, and was located with the help of public health midwife and GN officer. All other houses on the same side of the road immediately to the right of the index house were selected to each cluster. Out of the eligible members in each selected household, one was selected randomly after tossing a coin. Data collection was mostly done during weekends and public holidays to ensure that all those selected were available at home, especially the adult working males. Informed written consent was obtained from the study participants and at the end of data collection, they were made aware of their risk for colorectal cancer and the available screening tests.

A country-specific risk prediction model in the form of an interviewer-administered questionnaire was used to gather information on the risk of an adult developing colorectal cancer. The model used had been developed and validated by the authors, based on the findings of an unmatched case-control study conducted in the districts of Colombo and Gampaha among 65 clinically confirmed incident colorectal cancer cases and 130 colonoscopy negative controls. Its criterion validity and reliability had been assessed in another case-control study of 65 incident colorectal cancer cases and 65 hospital controls. The results proved the risk prediction model to be valid to detect those 'at risk' of developing colorectal cancer at the cut-off of 5.5 (score range: 0-25); sensitivity 76.9\% (95\% $\mathrm{CI}=66.7,87.1)$; specificity $83.1 \%(95 \% \mathrm{CI}=74.0,92.2$; area under the curve 0.849 (95\% CI=0.8, 0.9; $\mathrm{p}<0.001$ ) and reliable (test re-test kappa coefficient 0.88 ). The population 'at risk' was further categorized as having 'moderate' and 'high' risk using the cut-off scores of 5.5 to 9 and more than 9.1, respectively (14). Table 1 shows the model comprising eight risk predictors and their assigned weighted scores according to the risk category.

Data analysis was carried out using Statistical Package for Social Sciences (SPSS) version 20 software. The overall prevalence and 95\% confidence interval (CI) of those 'at risk' of developing colorectal cancer among adults was assessed. Further, the prevalence of 'moderate-risk' and 'high-risk' categories along with 95\% CI was assessed. Age-adjusted prevalence rates were calculated via direct method of standardization (15). The national population data according to 2012 census was used as the standard population to adjust for differences in the age distribution of the selected sample.

\section{Results}

Of the invited 825 eligible adults, 14 did not participate in the study, thus the response rate was $98 \%$. Reason for non-participation was unwillingness to spend time to respond to the questionnaire. Table 2 shows the socio-demographic characteristics of the study population while Table 3 depicts the presence of each predictor in the risk prediction model in the study population. 
Table 1. Predictor variables included in the risk prediction model for colorectal cancer

\begin{tabular}{|c|c|c|}
\hline Predictor variable & Categories & Score \\
\hline \multirow[t]{2}{*}{ Older age } & Less than 50 years & 0 \\
\hline & 50 years or more & 3 \\
\hline \multirow[t]{2}{*}{$\begin{array}{l}\text { Frequent consumption of deep fried food } \\
\text { for a period of } 20 \text { years or more }\end{array}$} & $\begin{array}{l}\text { Rare or never: less than } 3 \text { times per } \\
\text { week or never }\end{array}$ & 0 \\
\hline & Frequent: 3 or more times per week & 2 \\
\hline \multirow[t]{2}{*}{$\begin{array}{l}\text { Frequent consumption of red meat for a } \\
\text { period of } 20 \text { years or more }\end{array}$} & $\begin{array}{l}\text { Rare or never: less than } 3 \text { times per } \\
\text { week or never }\end{array}$ & 0 \\
\hline & Frequent: 3 or more times per week & 3 \\
\hline \multirow{2}{*}{$\begin{array}{l}\text { Diagnosis of colorectal cancer at or before } \\
60 \text { years among first degree relatives }\end{array}$} & No & 0 \\
\hline & Yes & 5 \\
\hline Diagnosis of other cancer at or before & No & 0 \\
\hline $\begin{array}{l}60 \text { years (breast, endometrial, ovary) } \\
\text { among first degree relatives }\end{array}$ & Yes & 3 \\
\hline \multirow{2}{*}{$\begin{array}{l}\text { Personal history of intestinal polyps } \\
\text { diagnosed before } 10 \text { years } \\
\text { (histologically confirmed) }\end{array}$} & No & 0 \\
\hline & Yes & 3 \\
\hline \multirow{2}{*}{$\begin{array}{l}\text { Personal history of hypertension for more } \\
\text { than } 10 \text { years (medically confirmed) }\end{array}$} & No & 0 \\
\hline & Yes & 3 \\
\hline \multirow{2}{*}{$\begin{array}{l}\text { Diagnosis of inflammatory bowel disease } \\
\text { before } 10 \text { years (histologically confirmed) }\end{array}$} & No & 0 \\
\hline & Yes & 3 \\
\hline \multicolumn{2}{|l|}{ Total } & 25 \\
\hline
\end{tabular}

Table 2. Socio-demographic characteristics of the study population $(\mathbf{N}=\mathbf{8 1 1})^{1}$

\begin{tabular}{lcc}
\hline Characteristic & No. & \% \\
\hline Age & & 40.9 \\
Less than 50 years & 332 & 59.1 \\
50 years or more & 479 & \\
\hline Sex & & 52.8 \\
Female & 428 & 47.2 \\
Male & 383 & \\
\hline Ethnicity & & 85.7 \\
Sinhala & 695 & 6.8 \\
Tamil & 55 & 7.3 \\
Muslim & 59 & 0.2 \\
Other & 2 & 77.4 \\
\hline Religion & & 7.2 \\
Buddhist & & 10.0 \\
Hindu & 628 & \\
Islam & 44 & \\
Catholic/Christian & 58 & \\
\hline
\end{tabular}


Highest educational level

\begin{tabular}{|c|c|c|}
\hline No schooling & 21 & 2.6 \\
\hline Grade 1 - 5 & 72 & 8.9 \\
\hline Grade 6 - 10 & 168 & 20.7 \\
\hline GCE O/L completed ${ }^{2}$ & 314 & 8.7 \\
\hline Grade 11 - 12 & 7 & 0.8 \\
\hline GCE A/L completed ${ }^{2}$ & 187 & 3.1 \\
\hline Technical/Professional diploma & 12 & \\
\hline University education & 30 & 7 \\
\hline
\end{tabular}

\section{Current marital status}

Single $\quad 29 \quad 3.6$

Legally married or living together $\quad 727 \quad 89.6$

$\begin{array}{lll}\text { Separated, widowed or divorced } & 55 & 6.8\end{array}$

\begin{tabular}{lrr}
\hline Current occupation & & \\
Unemployed/ Housewife/ Retired & 281 & 34.6 \\
Professional & 27 & 3.3 \\
Clerical & 33 & 4.1 \\
Service workers & 55 & 6.8 \\
Skilled & 86 & 10.6 \\
Trade & 161 & 19.9 \\
Elementary & 147 & 18.1 \\
Armed Forces & 21 & 2.6 \\
\end{tabular}

${ }^{1}$ Total for each variable; ${ }^{2}$ General Certificate of Education Ordinary Level and Advanced Level

Table 3. Distribution of the study population by each predictor of the risk prediction model $(\mathbf{N}=\mathbf{8 1 1})^{1}$

\begin{tabular}{|c|c|c|c|}
\hline Predictor variable & Categories & No. & $\%$ \\
\hline \multirow[t]{2}{*}{ Older age } & Less than 50 years & 332 & 40.9 \\
\hline & 50 years or more & 479 & 59.1 \\
\hline \multirow[t]{2}{*}{$\begin{array}{l}\text { Frequent consumption of deep fried food for a } \\
\text { period of } 20 \text { years or more }\end{array}$} & $\begin{array}{l}\text { Rare or never: less than } 3 \text { times } \\
\text { per week or never }\end{array}$ & 606 & 74.7 \\
\hline & Frequent: 3 or more times per week & 205 & 25.3 \\
\hline \multirow[t]{2}{*}{$\begin{array}{l}\text { Frequent consumption of red meat for a } \\
\text { period of } 20 \text { years or more }\end{array}$} & $\begin{array}{l}\text { Rare or never: less than } 3 \text { times } \\
\text { per week or never }\end{array}$ & 681 & 84.0 \\
\hline & Frequent: 3 or more times per week & 130 & 16.0 \\
\hline \multirow{2}{*}{$\begin{array}{l}\text { Diagnosis of colorectal cancer at or } \\
\text { before } 60 \text { years among first degree relatives }\end{array}$} & No & 798 & 98.4 \\
\hline & Yes & 13 & 1.6 \\
\hline \multirow{2}{*}{$\begin{array}{l}\text { Diagnosis of intestinal polyps } \\
\text { before } 10 \text { years (histologically confirmed) }\end{array}$} & No & 804 & 99.1 \\
\hline & Yes & 7 & 0.9 \\
\hline \multirow{2}{*}{$\begin{array}{l}\text { Diagnosis of other cancer at or } \\
\text { before } 60 \text { years (breast, endometrial, ovary) } \\
\text { among first degree relatives }\end{array}$} & No & 743 & 91.6 \\
\hline & Yes & 68 & 8.4 \\
\hline \multirow{2}{*}{$\begin{array}{l}\text { Personal history of hypertension for more } \\
\text { than } 10 \text { years (medically confirmed) }\end{array}$} & No & 745 & 91.9 \\
\hline & Yes & 66 & 8.1 \\
\hline \multirow{2}{*}{$\begin{array}{l}\text { Diagnosis of inflammatory bowel disease } \\
\text { before } 10 \text { years (histologically confirmed) }\end{array}$} & No & 809 & 99.8 \\
\hline & Yes & 2 & 0.2 \\
\hline
\end{tabular}

${ }^{1}$ Total for each variable 
The distribution of summary risk score was positively skewed (standardized skewness: 0.747 ). The range of summary risk score was 0 to 15 . The median of the summary score was 3 (IQR=2 to 5). According to the risk prediction model, among the study population ( $\mathrm{n}=811$ ), 125 individuals had scored more than 5.5 points. After adjusting for the differences in age categories, the age-adjusted prevalence rate of the population 'at risk' of developing colorectal cancer was $12.5 \%$ (95\% CI=12.3, 12.7). Among the 'moderaterisk' individuals $(\mathrm{n}=114)$ who have scored between 5.5 and 9 , the age-adjusted prevalence was $11.8 \%$ (95\% $\mathrm{CI}=11.6,12.0$ ) while the age-adjusted prevalence of high-risk individuals $(\mathrm{n}=11)$ who have scored more than 9.1 was $0.72 \%(95 \%$ CI $=0.7,0.8)$ (Table 4$)$.
Prevalence of being 'at risk' of developing colorectal cancer among the males (10.4\%; 95\% $\mathrm{CI}=8.4,12.6$ ) was significantly higher than that among the females (4.8\%; 95\% CI=3.7, 6.8). Similarly, the prevalence of being 'at risk' of developing colorectal cancer among Sinhalese (11.2\%; 95\% CI=9.2, 13.6) was significantly higher than that among the nonSinhalese (4.2\%; 95\% CI=3.0, 5.8). Finally, the prevalence of being 'at risk' of developing colorectal cancer among the participants who had highest education level of GCE O/Level or more (8.6\%; 95\% $\mathrm{CI}=6.9,10.8$ ) was overlapping and not significantly different from that among the participants who had highest education level of less than GCE. O/Level (6.8\%; 95\% CI=5.2, 8.7) (Table 5).

Table 4. Prevalence of 'at risk' population by age categories and age-standardized prevalence

\begin{tabular}{lccc}
\hline Age & $\begin{array}{c}\text { High-risk } \\
\text { prevalence }(>\mathbf{9 . 1}) \\
(\mathbf{9 5 \%} \mathbf{C I})\end{array}$ & $\begin{array}{c}\text { Moderate-risk } \\
\text { prevalence (5.5-9.1) } \\
\mathbf{( 9 5 \% ~ C I )}\end{array}$ & $\begin{array}{c}\text { Low-risk } \\
\text { prevalence }(<5.5) \\
\mathbf{( 9 5 \% ~ C I ) ~}\end{array}$ \\
\hline $\begin{array}{l}\text { Less than 50 years } \\
50 \text { years or more }\end{array}$ & $\begin{array}{c}0.23 \%(0.2-0.3 \%) \\
0.49 \%(0.4-0.5 \%)\end{array}$ & $\begin{array}{c}7.82 \%(7.7-8.0 \%) \\
3.94 \%(3.8-4.1 \%)\end{array}$ & $\begin{array}{c}68.35 \%(68.1-68.6 \%) \\
19.17 \%(18.9-19.4 \%)\end{array}$ \\
\hline Age standardized prevalence & $\begin{array}{c}0.72 \%(0.7-0.8 \%) \\
(\mathrm{n}=11)\end{array}$ & $\begin{array}{c}11.77 \%(11.6-12.0 \%) \\
(\mathrm{n}=114)\end{array}$ & $\begin{array}{c}87.52 \%(87.3-87.7 \%) \\
(\mathrm{n}=686)\end{array}$ \\
\hline
\end{tabular}

Table 5. Prevalence of those 'at risk' for developing colorectal cancer among the study population by selected socio-demographic characteristics $(\mathrm{N}=\mathbf{8 1 1})^{1}$

\begin{tabular}{|c|c|c|c|}
\hline Characteristic & $\begin{array}{c}\text { No. 'at risk' } \\
\quad(\mathrm{N}=125)^{\mathrm{a}}\end{array}$ & $\begin{array}{c}\% \\
(\mathrm{a} / \mathbf{8 1 1})\end{array}$ & $95 \% \mathrm{CI}$ \\
\hline
\end{tabular}

\section{Age}

50 years or more

$90 \quad 11.1$

(9.1-13.4)

Less than 50 years

$35 \quad 4.3$

(3.1-5.9)

Sex

Female

$41-4.8$
84

(3.7-6.8)

Male

$84 \quad 10.4$

(8.4-12.6)

\section{Ethnicity}

Sinhalese

$91 \quad 11.2$

(9.2-13.6)

Non-Sinhalese

34

4.2

(3.0-5.8)

Highest level of education

$\geq$ GCEO/Level

$70 \quad 8.6$
55

8.6

$(6.9-10.8)$

$<$ GCE O/Level

55

6.8

(5.2-8.7)

${ }^{1}$ Total Population; 'Includes the 125 persons who were 'at risk' of developing colorectal cancer 


\section{Discussion}

A descriptive cross-sectional study design was used to estimate the prevalence of those 'at risk' of developing colorectal cancer among adults, using a risk prediction model developed and validated locally. The study employed the most feasible technique to obtain the sample in a community-based study, the cluster sampling technique further minimizing the selection bias. Non-response was kept to a minimum by visiting the households during times when the working or employed study units were likely to be present at home and re-visiting them by given appointments to suit the respondent with minimum discomfort. Several measures were also taken to maintain the quality of the data gathered. The model contained only eight predictors and was formulated as an interviewer-administered questionnaire which allowed uniform collection of data from study units with any educational background and even from the illegible persons. Including simple comprehensive closeended questions needing less effort to recall also addressed the issue of recall bias. Accuracy of the information related to medical or surgical conditions were verified through records. However, it should be noted that the cut-off scores to identify 'high-risk' and 'moderate-risk' was through group consensus of the expert panel and not via a psychometric validation method which is a drawback in this study.

The sample included a higher proportion of individuals aged 50 years or more, which is not representative of the age distribution of the general population. To overcome this measure, the study incorporated the direct method of standardization in comparison with the general population from the census in 2012 as the standard population. This produced the age- adjusted prevalence of the population at risk to be $12.5 \%(95 \% \mathrm{CI}=12.3,12.7)$ from the non-adjusted prevalence rate of $15.4 \%$.

Since this study used a validated risk prediction model and cut-off points determined through validation using a gold standard, this value can be considered to be a valid estimate of the 'at risk' adults for developing colorectal cancer in the population. More than 50 countries have adopted the use of risk prediction models for identifying the high-risk population for colorectal cancer, since risk stratification has benefitted on giving the diagnostic services for the needed (16). However, an extensive search on global literature failed to identify research on the prevalence of those 'at risk' of developing colorectal cancer, which prevents the opportunity of comparing the validity of results with similar studies. The only study available was by Kumari BV in 2013 (17), demonstrating the 'at risk' prevalence of developing breast cancer of $39.4 \%$ (95\% CI $=36.7$, 42.1) among adults in the district of Colombo, based on a locally developed and validated risk prediction model for breast cancer in Sri Lanka.

Having a high 'at risk' prevalence (12.5\%) of developing colorectal cancer can have major implications. Providing definitive diagnostic test facilities such as colonoscopy or flexible sigmoidoscopy examinations for those with positive results which are invasive and costly becomes an issue. On the other hand, human resources to perform this procedure in the state sector is also lacking widely. Keeping this in mind, the present risk prediction model was designed with two further cut-offs to assess moderate- and high-risk groups. The plan was to identify a sub-group of the high-risk population on whom the diagnostic test can be applied immediately following the screening, while identifying a sub-group with moderate-risk to be monitored with preventive advice and follow-up screening. The results indicate that the model was successful in identifying a proportion of 'high-risk' population which is amenable to be referred for colonoscopy or flexible sigmoidoscopy examination.

\section{Conclusions and Recommendations}

Age-adjusted estimated prevalence of the population 'at risk' for developing colorectal cancer among adults in the districts of Colombo and Gampaha was relatively high, with 12 out of every 100 persons identified as being at risk. While it indicates the need for advocating a screening test for colorectal cancer in Sri Lanka within the existing health system, it further highlights the logistical difficulties in offering followup diagnostic tests to all those screened-positive. Thus, the study recommends this risk prediction model to be incorporated into the NCD screening programme at HLCs in Sri Lanka. Consequently, the identified highrisk groups can be referred for diagnostic tests, while those at moderate-risk can be advised on lifestyle modification and monitored with follow-up screening. 


\section{Public health implications}

The relatively high 'at risk' prevalence denotes the burden of colorectal cancer on the health system in future. It is likely that the quality of life and survival of colorectal cancer will be improved by early detection, if the risk prediction model is successful at primary care level. With the availability of a risk prediction model for early detection of colorectal cancer, the scope of healthy lifestyle centres can be extended to cancer screening. This study also provides the baseline for future research on possible interventions for those at moderate-risk.

\section{Author Declarations}

Competing interests: The authors declare that there are no financial or non-financial competing interests.

Ethics approval and consent to participate: Informed written consent was obtained from all study participants, and the study was approved by the Ethics Review Committee of Faculty of Medicine, University of Colombo, Sri Lanka (ERC number EC-15-078). Following data collection, each participant was made aware of their risk for colorectal cancer and the available screening methods.

Funding: This study was funded by the Medical Research Institute, Ministry of Health, Sri Lanka. The funding agency did not have any role in the design of this study, data collection, data interpretation and manuscript writing.

Acknowledgments: Authors wish to thank health administrators of the districts, clinicians of the institutions and participants of the study for their support and participation.

Author contribution: YMS contributed to the conception and the design of the study, performed data collection, data analysis, interpretation of data and drafting the manuscript. NSG contributed to the conception and the design of the study, participated in the data analysis, interpretation of data and revising the article for important intellectual content. AP contributed to the conception and the design of the study, participated in interpretation of data and revising the article for important intellectual content. All authors read and approved the final version to be submitted.

\section{References}

1. GLOBOCAN 2012. Colorectal cancer: estimated incidence, mortality and prevalence worldwide in 2012. Geneva: World Health Organization, 2015. Available from: http://globocan iarc.fr/Pages/ fact_sheets_cancer.aspx\#.

2. Boyle P\& Leon ME. Epidemiology of colorectal cancer. British Medical Bulletin 2002; 64(1): 1-25.

3. National Cancer Control Programme. Cancer incidence data Sri Lanka 2010. Colombo: Ministry of Health, 2016.

4. Bretthauer M. Colorectal cancer screening. Journal of Internal Medicine 2011; 270: 87-98.

5. Levin B, Lieberman DA, McFarland B, Robert AS, Andrews KS, Brooks D, Dash C, Giardiello FM, Glick S, Levin TR, Pickhardt P, Rex DK, Thorson A, Winawer SJ; American Cancer Society Colorectal Cancer Advisory Group; US Multi-Society Task Force; American College of Radiology Colon Cancer Committee. Screening and surveillance for the early detection of colorectal cancer and adenomatous polyps, 2008: a joint guideline from the American Cancer Society, the US Multi-Society Task Force on Colorectal Cancer and the American College of Radiology. Gastroenterology 2008; 134(5): 1570-1595.

6. Win AK, Macinnis RJ, Hopper JL, Jenkins MA. Risk prediction models for colorectal cancer: a review. Cancer Epidemiological Biomarkers Prevention 2011; 21(3): 398-410.

7. Freedman AN, Slattery ML, Ballard-Barbash R, Willis G, Cann BJ, Pee D, Gail MH, Pfeiffer RM. Colorectal cancer risk prediction tool for white men and women without known susceptibility. Journal of the National Cancer Institute 2009; 27(5): 686-693.

8. Colditz GA, Atwood KA, Emmons K, Monson RR, Willett WC, Trichopoulos D, Hunter DJ. Harvard report on cancer prevention volume 4: Harvard Cancer Risk Index. Risk Index Working Group, Harvard Center for Cancer Prevention. Cancer Causes Control 2000; 11(6): 477-488.

9. Driver JA, Gaziano JM, Gelber RP, Lee IM, Buring JE, Kurth T. Development of a risk score for colorectal cancer in men. American Journal of Medicine 2007; 120(3): 257-263.

10. Mallawaarachchi DSV, Wickramasinghe SC, Somatunga LC, Siriwardana VTSK, Gunawardana NS. Healthy lifestyle centres: a service for screening non- 
communicable diseases through primary healthcare institutions in Sri Lanka. WHO South-East Asia Journal of Public Health 2016; 5(2): 89-95.

11. DCS. Census of Population and Housing 2012. Colombo: Department of Census and Statistics, 2012.

12. Lwanga SK \& Lemeshow S. Sample size determination in health studies: a practical manual. Geneva: World Health Organization, 1991.

13. Bennett S, Woods T, Liyanage WM, Smith DLA. A simplified general method for cluster-sample surveys of health in developing countries. World Health Statistics Quarterly 1991; 44(3): 98-106.

14. Samarakoon YM. Risk factors and risk prediction of colorectal cancer among adults in the districts of Colombo and Gampaha. MD thesis (Community
Medicine). Colombo: Post Graduate Institute of Medicine, 2016.

15. Gretens E. Age adjusted rate. Data Surveillance Systems and Statistical Reports, Missouri Department of Health and Senior Services.

Available from http:// health. mo.gov /data /mica/ CDP_MICA/AARate.html.

16. Usher-Smith JA, Walter FM, Emery JD, Win AK, Griffin SJ. Risk prediction models for colorectal cancer: a systematic review. Cancer Prevention Research 2016; 9(1): 13-26.

17. Kumari PBVR. Risk factors and risk assessment of breast cancer among women in the district of Colombo. MD thesis (Community Medicine). Colombo: Post Graduate Institute of Medicine, 2013. 